\title{
Predictors of hospital and one-year mortality in intensive care patients with refractory status epilepticus: a population- based study
}

Anne-Mari Kantanen ${ }^{1 *}$, Reetta Kälviäinen ${ }^{2}$, Ilkka Parviainen ${ }^{3}$, Marika Ala-Peijari ${ }^{4}$, Tom Bäcklund ${ }^{5}$, Juha Koskenkari' Ruut Laitio $^{7}$ and Matti Reinikainen ${ }^{8}$

\begin{abstract}
Background: The aim was to determine predictors of hospital and 1-year mortality in patients with intensive care unit (ICU)-treated refractory status epilepticus (RSE) in a population-based study.

Methods: This was a retrospective study of the Finnish Intensive Care Consortium (FICC) database of adult patients (16 years of age or older) with ICU-treated RSE in Finland during a 3-year period (2010-2012). The database consists of admissions to all 20 Finnish hospitals treating RSE in the ICU. All five university hospitals and 11 out of 15 central hospitals participated in the present study. The total adult referral population in the study hospitals was 3.92 million, representing $91 \%$ of the adult population of Finland. Patients whose condition had a post-anoxic aetiological basis were excluded.

Results: We identified 395 patients with ICU-treated RSE, corresponding to an annual incidence of 3.4/100,000 (95\% confidence interval (Cl) 3.04-3.71). Hospital mortality was 7.4\% (95\% Cl 0-16.9\%), and 1-year mortality was 25. $4 \%$ (95\% Cl 21.2-29.8\%). Mortality at hospital discharge was associated with severity of organ dysfunction. Mortality at 1 year was associated with older age (adjusted odds ratio (aOR) 1.033, 95\% Cl 1.104-1.051, $p=0.001$ ), sequential organ failure assessment (SOFA) score (aOR 1.156, Cl 1.051-1.271, $p=0.003$ ), super-refractory status epilepticus (SRSE) (aOR 2.215,95\% Cl 1.20-3.84, $p=0.010$ ) and dependence in activities of daily living (ADL) (aOR 2.553, 95\% Cl $1.537-4.243, p<0.0001)$.

Conclusions: Despite low hospital mortality, 25\% of ICU-treated RSE patients die within a year. Super-refractoriness, dependence in $A D L$ functions, severity of organ dysfunction at ICU admission and older age predict long-term mortality.
\end{abstract}

Trial registration: Retrospective registry study; no interventions on human participants.

Keywords: Status epilepticus, Refractory status epilepticus, Super-refractory status epilepticus, Incidence, Mortality, ICU treatment, Outcome

\footnotetext{
* Correspondence: anne-mari.kantanen@kuh.fi

'Epilepsy Center, Neurocenter, Department of Neurology, Kuopio University

Hospital, Kuopio, Finland

Full list of author information is available at the end of the article
}

\section{Ciomed Central}

(c) The Author(s). 2017 Open Access This article is distributed under the terms of the Creative Commons Attribution 4.0 International License (http://creativecommons.org/licenses/by/4.0/), which permits unrestricted use, distribution, and reproduction in any medium, provided you give appropriate credit to the original author(s) and the source, provide a link to the Creative Commons license, and indicate if changes were made. The Creative Commons Public Domain Dedication waiver (http://creativecommons.org/publicdomain/zero/1.0/) applies to the data made available in this article, unless otherwise stated. 


\section{Background}

Status epilepticus (SE) is a neurological emergency that may cause death and marked neurological deficiency. SE is called refractory status epilepticus (RSE) if the firstline and second-line medication does not terminate the seizure, and it is referred to super-refractory SE (SRSE) if it continues over $24 \mathrm{~h}$ after the onset of the first anaesthesia [1]. Less than $50 \%$ of patients with SE have had previous seizures or epilepsy. There are several other aetiologies, but the cause is usually an underlying acute neurological disease, systemic disorder or condition with a remote aetiological basis after previous central nervous system injury [2, 3].

Data on the long-term outcomes of SE are scarce, particularly in the cases of RSE and SRSE, and they are based on small patient cohorts [4]. Age, aetiology of disease, type of seizure at onset, treatment delay, level of consciousness at presentation, use of electroencephalography (EEG) and delay in admission to the intensive care unit (ICU) are reported to affect outcomes [4-7]. Inhospital seizures seem to have worse outcomes than those starting outside the hospital setting [7, 8]. Moreover, there are both national and international guidelines and algorithms for better treatment of SE [2, 9-13]; however, the outcomes remain poor: Short-term mortality in adult SE and RSE vary in the range of 19$39 \%[6,14]$, while longer-term mortality is in the range of $35-43 \%[4,15]$. Long-term mortality in SRSE is twofold higher than in RSE alone [16]. The mortality of SE is correlated with seizure duration, rapid identification of SE and aetiology of disease [1].

Our study group has recently reported on the incidence of SRSE and the mortality rates in patients with SRSE from this same patient cohort [16]. The aim of the present study was to determine predictors of hospital and 1-year mortality in ICU-treated patients with RSE, including patients evolving to SRSE, in a nationwide population-based study.

\section{Methods}

\section{Data source}

The Finnish Intensive Care Consortium (FICC) is a body responsible for a national ICU benchmarking programme and database in Finland. All 20 major central and university hospitals, providing all secondary and tertiary care, ICUs and neurological services for their referral population in Finland, joined the consortium by 2007. The FICC database collects data from every ICU admission from all general adult ICUs in all 20 Finnish hospital districts.

Information on clinical characteristics, severity of illness and outcomes is collected in the database; this is validated by each participating ICU before submission to the central database [17]. All 5 university hospitals and
11 out of 15 central hospitals participated in the present study. Both ICU physicians and neurologists participate in the diagnostics and patient care in these ICUs. We used the FICC database and medical records to identify adult patients (age 16 years or over) with RSE treated with general anaesthesia in the ICU) in a populationbased cohort in Finland during the 3-year period of 2010-2012. This study received FICC Board approval to access the database, while the authorities responsible for specific hospital districts authorised the use of medical records data.

\section{Patients}

We included consecutive adult patients (age 16 years or older) with RSE treated with general anaesthesia. To identify patients treated in an ICU for seizure disorders, we first searched the FICC database for patients who had been classified under the acute physiology and chronic health evaluation (APACHE) II diagnostic group "seizure"' [18] or for whom one of the ICD-10 codes for epilepsy, SE or convulsions (G40.X, G41.X or R56.8) had been documented. We only included patients who had been treated in the ICU for at least $48 \mathrm{~h}$, which we estimated to be the minimum duration of treatment and weaning period for patients with RSE treated with general anaesthesia. Intensive care unit physicians at each participating hospital re-evaluated the patients' medical records to identify patients with RSE, that is, patients who had prolonged seizures that did not improve with firstline and second-line treatment with antiepileptic drugs (AEDs) and were treated with general anaesthesia in the ICU. Patients with post anoxic aetiologies were excluded. Altogether 395 incidents of RSE fulfilled the final inclusion criteria (Fig. 1).

\section{Clinical factors}

The simplified acute physiology score II (SAPS II) [19] and sequential organ failure assessment (SOFA) score [20] for the first $24 \mathrm{~h}$ in the ICU, describing the severity of organ failure and illness, were collected from the FICC database. Independence in activities of daily living (ADL) was coded as independent or nonindependent (with supervision, direction or personal assistance) as a measure of each patient's pre-morbid functional capacity. The Glasgow coma scale (GCS) for describing the impairment of consciousness was assessed at the time of ICU admission before any sedative medication was administered. Data on access to diagnostic EEG and continuous EEG monitoring during the ICU stay and data on the intravenous anaesthetics given were obtained from medical records by local intensive care physicians. 


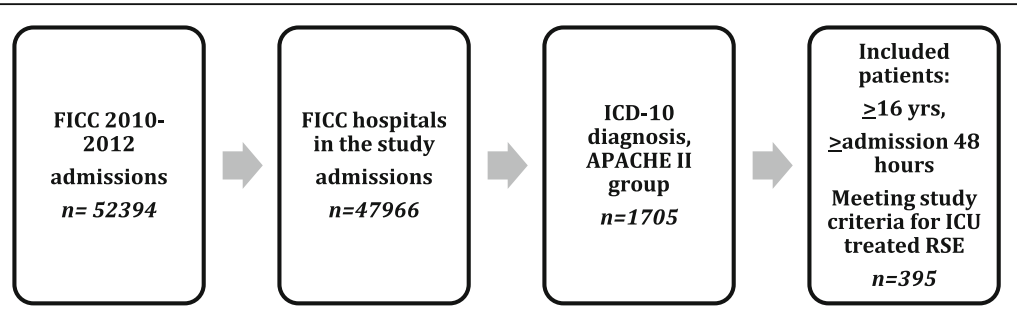

Fig. 1 Data collection flowchart. The Finnish Intensive Care Consortium (FICC) database had 52,394 ICU admissions in 2010-2012, and 395 patients met the study criteria of intensive care unit (ICU) general anaesthesia-treated refractory status epilepticus (RSE). APACHE acute physiology and chronic health evaluation

\section{Statistical analysis}

Statistical analyses were conducted using SPSS software version 22 (IBM Corp, Armonk, NY, USA). We calculated the population incidence for RSE and 95\% confidence intervals (CIs) for a single incidence rate. The chi-square test was used to compare the categorical variables, and nonparametric tests (Mann-Whitney $U$ for test for the median) were used with continuous variables. Variables that were significant in univariate analyses were included in binary logistic multivariate regression analysis with the backward likelihood-ratio technique and significance variance exclusion set at 0.10 .

\section{Results}

\section{Patients and incidence}

We identified 395 patients treated for RSE in the ICU during a 3 -year period. The adult population of the participating 16 hospital districts is 3.92 million, representing $91 \%$ of the total Finnish adult population. The annual incidence of ICU-treated RSE was 3.4/100,000 (95\% CI 3.04-3.71). Of the 395 patients, 264 (66.8\%) were treated in university hospitals. The median age of the patients was 58 years (interquartile range (IQR) 4667], and $245(62.3 \%)$ of the patients were male. The median length of the ICU stay was 5.0 days (IQR 3.5-8), and the overall median hospital stay was 13 days (IQR 8-21). Altogether, $112(28.2 \%)$ patients in the cohort needed help in their ADL functions before hospital treatment. Demographics and data are shown in Table 1.

\section{Diagnostics and treatment}

Diagnostic EEG data were available for 186 patients (47.1\%) and continuous EEG monitoring during anaesthesia was available for $313(80.1 \%)$ of the RSE patients. Altogether, 39 patients (9.9\%) had neither diagnostic nor continuous EEG monitoring. Propofol was given for 12$24 \mathrm{~h}$ as the first intravenous anaesthetic (IVA) in 373 of the patients (94.4\%), whereas thiopental was administered for $12-24 \mathrm{~h}$ in 17 patients (4.3\%). SRSE was identified in 87 patients $(22.0 \%)$.

\section{Mortality Hospital mortality}

The ICU mortality was 4/395 (1\%, 95\% CI 0-10.8\%), and total hospital mortality was 29/395 (7.4\%, 95\% CI 0-16.9\%). In multivariate regression analysis, the SOFA score was an independent predictor of hospital mortality. Neither age nor premorbid ADL stage predicted hospital mortality (Fig. 2, Table 2).

\section{One-year mortality}

A total of $366(92.7 \%)$ patients were discharged from hospital. Only $23.8 \%$ of the patients were discharged to home. Most patients (47.4\%) were discharged to primary healthcare wards and $21.0 \%$ to specialist care facilities. Ninety-nine patients (25.4\%, 95\% CI 21.2-29.8) died within 12 months of ICU admission. The discharge destination was highly predictive of outcomes at 12 months: only $5.4 \%$ of patients discharged to their home died, but mortality was $18.3 \%$ among those discharged to specialist care hospitals and $28.1 \%$ for patients discharged to primary care wards $(p=0.001)$. Mortality at 1 year was associated with older age, SRSE, severity of organ failure and lower premorbid capacity of ADL functions (Table 2). Both increasing age and poor premorbid functional performance were strong predictors of increased 1-year mortality (Fig. 2). Level of consciousness was measured by the GCS at presentation (median score 5 (IQR 4-10)), and there was no significant association with hospital mortality $(p=0.14)$ or 1 -year mortality $(p=0.11)$.

\section{Discussion}

Our study represents the first population-based, nationwide cohort showing the incidence and long-term mortality in ICU-treated and anaesthesia-treated RSE and SRSE. The incidence of RSE in our population-based cohort was 3.4/100,000/year, and the incidence SRSE in our cohort was $0.7 / 100,000 /$ year [16], constituting $22 \%$ of the patients with RSE. Depending on the definition of RSE that was used, 4-26\% of patients with RSE have previously been reported to develop SRSE [21]. According 
Table 1 Demographics and clinical characteristics by hospital and one-year mortality

\begin{tabular}{|c|c|c|c|c|c|c|c|}
\hline & & By hospital o & utcome $n=394$ & & By one-year c & utcome $n=390$ & \\
\hline & $\begin{array}{l}\text { All } \\
n=395\end{array}$ & $\begin{array}{l}\text { Survivors } \\
n=365\end{array}$ & $\begin{array}{l}\text { Non-survivors } \\
n=29\end{array}$ & $P$ value & $\begin{array}{l}\text { Survivors } \\
n=291\end{array}$ & $\begin{array}{l}\text { Non-survivors } \\
n=99\end{array}$ & $P$ value \\
\hline Age, years, median (IQR) & $58(46-67)$ & $58(43-67)$ & $62(54-73)$ & 0.033 & $55(41.5-65)$ & $62(53-72.5)$ & $<0.001$ \\
\hline Male, $n(\%)$ & $245(62.3 \%)$ & $229(62.7 \%)$ & $16(55.2 \%)$ & 0.41 & $185(63.6 \%)$ & $57(57.6 \%)$ & 0.25 \\
\hline Needing help in ADL, $n(\%)$ & $112(28.3 \%)$ & $103(28.2 \%)$ & $9(31.0 \%)$ & 0.72 & $67(23.0 \%)$ & $44(44.4 \%)$ & $0.000037<0.001$ \\
\hline SAPS II, median (IQR) & $47(36.5-57)$ & $47(36-57)$ & $56(47-60)$ & 0.003 & $45(35-55)$ & $52(43-61)$ & $<0.001$ \\
\hline SOFA, median (IQR) & $8(6-10)$ & $8(6-10)$ & $10(8-11)$ & 0.005 & $8(6-10)$ & $9(7-11)$ & 0.003 \\
\hline SOFA score without CNS points, median (IQR) & $5(4-6)$ & $5(4-6)$ & $6(4.5-9)$ & 0.005 & $5(4-6)$ & $5(4-7)$ & 0.013 \\
\hline GCS, median (IQR) & $5(4-10)$ & $6(4-10)$ & $5(3-7.5)$ & 0.14 & $6(4-10)$ & $5(3-8)$ & 0.11 \\
\hline GCS <6, n (\%) & $195(49.3 \%)$ & $178(48.8 \%)$ & 17 (58.6\%) & 0.25 & $149(51.2 \%)$ & $42(42.4 \%)$ & 0.11 \\
\hline SRSE, $n(\%)$ & $87(22.0 \%)$ & $78(21.4 \%)$ & $9(31.0 \%)$ & 0.15 & $54(18.4 \%)$ & $30(30.3 \%)$ & 0.011 \\
\hline Admission from ward, $n(\%)$ & $71(18.0 \%)$ & $63(17.3 \%)$ & $8(26.7 \%)$ & 0.16 & $45(15.5 \%)$ & $25(25.3 \%)$ & 0.029 \\
\hline LOS ICU, median (IQR) & $5.0(3.5-8.0)$ & $5.0(3.5-7.8)$ & $6.5(4.1-10)$ & 0.048 & $4.9(3.2-7.8)$ & $5.8(3.9-9.1)$ & 0.054 \\
\hline LOS hospital, median (IQR) & $13(8-21)$ & $13(8-22)$ & $12(8-19)$ & 0.77 & $13(8-21)$ & $14(9-22)$ & 0.27 \\
\hline Hospital discharge & & & & & & & 0.001 \\
\hline Home, $n(\%)$ & $94(23.8 \%)$ & & & & $88(30.2 \%)$ & $5(5.0 \%)$ & \\
\hline Specialist care hospital/ward, $n$ (\%) & $86(21.0 \%)$ & & & & $67(23.0 \%)$ & $15(11.3 \%)$ & \\
\hline Primary care hospital/ward, $n(\%)$ & $185(47.4 \%)$ & & & & $133(45.7 \%)$ & $52(28.1 \%)$ & \\
\hline Died in hospital, $n$ (\%) & $29(7.4 \%)$ & & & & & & \\
\hline
\end{tabular}

ADL activities of daily living, SAPS // simplified acute physiology score II, SOFA sequential organ failure assessment, GCS Glasgow coma scale, SRSE super-refractory status epilepticus, LOS length of stay, ICU intensive care unit

to Delaj et al. [21], if all patients with RSE are included, the frequency of SRSE is $4 \%$, and if only intubated patients with RSE are included (as in our study), the frequency is $42 \%$.

The rates of ICU mortality (1\%) and hospital mortality $(7 \%)$ in our study are comparable with recently reported rates of ICU mortality (2\%) and hospital mortality (5\%) in Australia and New Zealand [22], although this study included all prolonged seizures and not only RSE. The 1 -year mortality rate $(25 \%)$ in RSE in the present population-based study is relatively low compared to those reported in earlier studies, in which long-term mortality was in the rage of $26-62 \%$ (time variance of 1-12 months) [4, 23-26]. Consequently, the outcome in patients with RSE deteriorates after the period of stay in the ICU and the first weeks of hospitalisation, and one fourth of these patients die within a year.

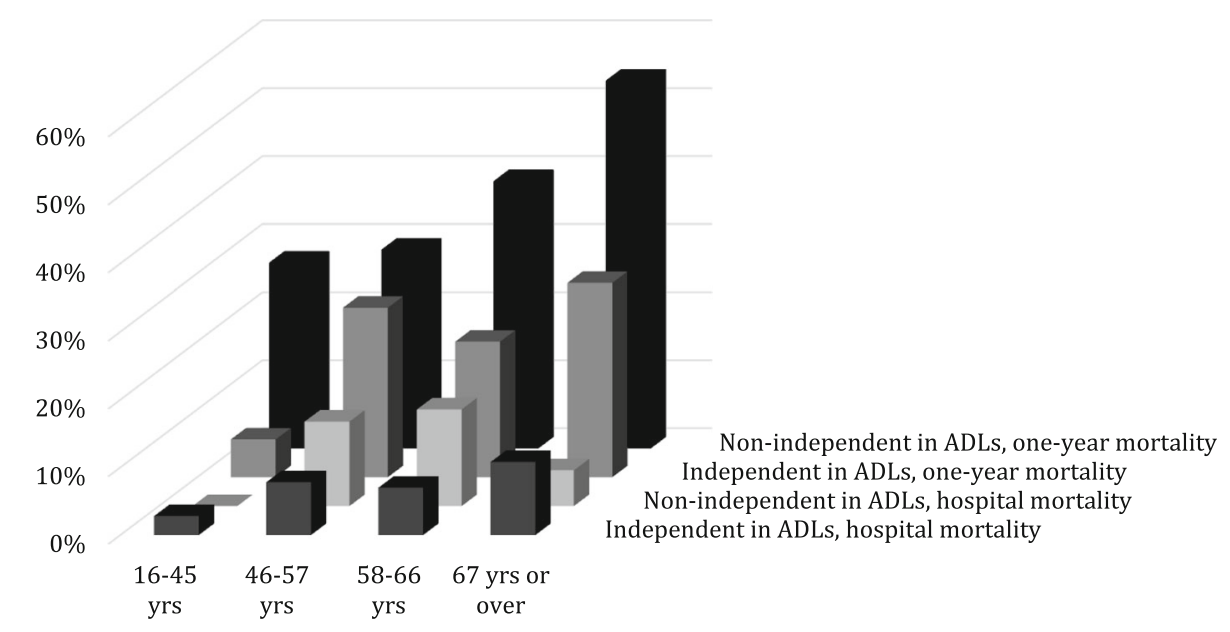

Fig. 2 Hospital and one-year mortality by age quartiles and premorbid functional status. ADLs activities of daily living 
Table 2 Predictors of hospital and one-year mortality

\begin{tabular}{|c|c|c|c|c|c|c|}
\hline \multirow[t]{2}{*}{ Predictor } & \multicolumn{3}{|c|}{ Univariate analysis } & \multicolumn{3}{|c|}{ Multivariate analysis } \\
\hline & $\mathrm{OR}$ & $95 \% \mathrm{Cl}$ & $P$ value & Adjusted OR & $95 \% \mathrm{Cl}$ & $P$ value \\
\hline \multicolumn{7}{|l|}{ Hospital mortality } \\
\hline Age & 1.030 & $1.002-1.059$ & 0.039 & & & NS \\
\hline Male gender & 0.73 & $0.34-1.56$ & 0.41 & & & NS \\
\hline Non-independence in ADL & 1.16 & $0.51-2.66$ & 0.72 & & & NS \\
\hline SOFA & 1.25 & $1.09-1.44$ & 0.002 & 1.22 & $1.06-1.41$ & 0.007 \\
\hline GCS & 0.93 & $0.83-1.04$ & 0.18 & & & NS \\
\hline SRSE & 1.83 & $0.79-4.24$ & 0.16 & 2.04 & $0.86-4.84$ & 0.104 NS \\
\hline Admission from ward & 1.83 & $0.77-4.31$ & 0.17 & & & NS \\
\hline \multicolumn{7}{|l|}{ One-year mortality } \\
\hline Age & 1.04 & $1.02-1.06$ & $<0.001$ & 1.03 & $1.01-1.05$ & $<0.001$ \\
\hline Male gender & 0.76 & $0.48-1.22$ & 0.25 & & & NS \\
\hline Non-independence ADL & 2.73 & $1.68-4.44$ & $<0.001$ & 2.55 & $1.46-4.13$ & 0.001 \\
\hline SOFA & 1.16 & $1.07-1.27$ & 0.001 & 1.17 & $1.06-1.30$ & 0.002 \\
\hline GCS & 0.95 & $0.89-1.01$ & 0.084 & & & \\
\hline SRSE & 1.95 & $1.16-3.29$ & 0.012 & 2.215 & $1.20-3.84$ & 0.010 \\
\hline Admission from ward & 1.84 & $1.06-3.20$ & 0.031 & 1.73 & $0.94-3.2$ & $0.08 \mathrm{NS}$ \\
\hline
\end{tabular}

OR odds ratio, $C I$ confidence interval, $A D L$ activities of daily living, SOFA sequential organ failure assessment, GCS Glasgow coma scale, SRSE super-refractory status epilepticus, NS not significant. $P$ values in italics are statistically significant

We found that older age, SRSE, premorbid dependence in ADL and severity of organ dysfunction are associated with unfavourable long-term outcomes. Our data show that mortality doubles within 12 months if the patient needs help in ADL functions before the RSE incident and ICU admission. SOFA scores defining patient organ dysfunction and comorbidities are associated with poor long-term outcomes. Age and comorbidities have also been reported as measures of poor outcome in other studies of RSE [27-30]. The question remains as to whether it is the RSE, the aetiology of RSE, the patient's pre-existing characteristics or the ICU treatment that explains the poor long-term outcome. This phenomenon is also seen in other ICU cohorts and studies of other diseases [31-33]. Age, comorbidities and frailty have major effects on the long-term outcomes of intensive care in general. In this study, level of consciousness measured by GCS at presentation to ICU did not predict mortality. This finding is in accordance with earlier studies by Sutter et al. $[5,34]$ in patients with RSE after excluding patients with hypoxic-ischaemic encephalopathy, as we have done in this cohort.

Consistency with the Finnish Current Care guideline was good in the choice of the first intravenous anaesthetic (IVA): propofol, the suggested drug, was used in 94\% of patients [9]. Compliance with the guideline in access to diagnostic EEG and continuous EEG monitoring during anaesthesia was lower. Diagnostic EEG evaluation was used in less than half of the patients (47\%), and continuous EEG monitoring was employed in $80 \%$ of patients. However, only $10 \%$ of the patients were treated without any EEG evaluation. RSE diagnostics should include EEG along with clinical judgement to differentiate between seizure activity, post seizure and medicationderived conditions and non-epileptic seizures (NES).

Patients can also be attended in the emergency department (ED) after having been sedated and intubated by paramedics and emergency doctors; therefore, evaluation of ongoing seizure activity and clinical presentation is necessary. Monitoring the depth of the coma and suppression of seizure activity, and secondarily, burst suppression (BS), is essential when titrating the depth of anaesthesia $[9,10]$.

Our study demonstrated that access to diagnostic EEG and continuous EEG monitoring during on-call hours is still not perfectly organised nationwide. This problem seems to be international; according to a recent article only $33 \%$ of the hospital trusts treating RSE in the UK had access to continuous EEG [35]. In our cohort, patients with no EEG data (10\% of patients) were diagnosed as having RSE patients based on clinical judgement only. Unfortunately we have no data on AED management during the withdrawal of anaesthetics in the present study. This would be important because failure of the first anaesthesia and the occurence of SRSE may unnecessarily occur after inadequate use of background AEDs and not due to the refractoriness of the SE itself. Concomitant AED therapy should be started to 
prevent the recurrence of RSE, and it should be continued parallel to the acute emergency treatment to ensure adequate levels of AED medication both with intravenous preparations and via the nasogastric tube or percutaneus endoscopic gastrostomy if necessary. Patients with preexisting epilepsy should have their previous antiepileptic medications continued with optimised doses [10].

ICU admission from a ward as compared to admission from the ED or other monitoring units was associated with 1-year mortality in univariate analysis. However, in our study there was no independent effect in multivariate analysis when adjusting for other risk factors. In some earlier studies hospitalised patients had RSE of more severe aetiology: focal brain abnormalities (stroke, tumour or trauma) or systemic metabolic disturbances had a worse outcome associated with the aetiology of the condition $[8,36]$. In addition, as seizure duration over $1 \mathrm{~h}$ and especially over $24 \mathrm{~h}$ is associated with greater mortality in patients with RSE, a longer delay in treatment may be a factor in the poorer prognosis for patients with in-hospital RSE. Seizures are better recognised in the ED and monitoring units than in an inpatient ward setting $[15,37]$.

\section{Study limitations}

A retrospective registry study has limitations: this nationwide study lacked information on the aetiology of RSE and long-term neurological outcomes apart from mortality. In addition, we did not have data on patients who may have had RSE but were treated outside of ICUs because of the presumed futility of intensive care. However, this is a large population-based study of 395 patients with ICU-treated RSE. The referral population of the participating hospitals represents over $90 \%$ of the Finnish population, and all major hospital districts and university hospitals with their catchment areas were included. We consider this study population highly representative of all patients with ICU-treated RSE in Finland.

\section{Conclusions}

We conclude that ICU-treated RSE is a neurological emergency with a substantial 1-year mortality rate. Despite low mortality rates in the ICU and in hospital, $25 \%$ of the patients in our study died within a year. Older age, SRSE, premorbid non-independence in ADL functions and severity of organ failure predicted mortality at 1 year. Early effective treatment and preventing SE from developing into RSE would probably represent the best treatment actions to reduce mortality in RSE. Intensive care and general anaesthesia are the mainstays of treatment for RSE. Elderly or otherwise frail patients with impaired functional performance should be identified early and evaluated thoroughly individually; such patients should possibly be treated with a less aggressive method.

\section{Abbreviations}

ADL: Activities of daily living; AED: Antiepileptic drug; APACHE: Acute physiology and chronic health evaluation; Cl: Confidence interval; ED: Emergency department; EEG: Electroencephalography; FICC: Finnish Intensive Care Consortium; GCS: Glasgow coma scale; ICU: Intensive care unit; IQR: Interquartile range; IVA: Intravenous anaesthetic; RSE: Refractory status epilepticus; SAPS: Simplified acute physiology score; SE: Status epilepticus; SOFA: Sequential organ failure assessment; SRSE: Super-refractory status epilepticus

\section{Acknowledgements \\ The authors acknowledge FICC hospital intensive care physicians: Raili Larusompa (Central Finland Central Hospital); Pekka Saastamoinen (East Savo Central Hospital); Johanna Wennevirta (Helsinki University Hospital); Outi Kiviniemi (Lapland Central Hospital); Tadeusz Kamiski (Middle Ostrobothnia Central Hospital); Antti-Pekka Loisa (Päijät-Häme Central Hospital); Atte Koskinen (Satakunta Hospital District); Sari Melto and Kirsi Anne (South Karelia Central Hospital); Heikki Laine (South Savo Central Hospital); Kari Saarinen(South Ostrobothnia Central Hospital); Sari Karlsson (Tampere University Hospital) and Simo-Pekka Koivisto (Vaasa Central Hospital).}

\section{Funding}

This study was supported by grants from the Kuopio University Hospital Special Government Funding (VTR, 507 T006), Finnish Epilepsy Research Foundation and Finnish Cultural Foundation and Saastamoinen Foundation. The funding agencies had no role in data collection, analysis or interpretation, writing the report or the decision to submit the paper for publication.

Availability of data and materials

The datasets used and analysed during the current study are available from the corresponding author on reasonable request.

\section{Authors' contributions}

AMK, MR, RK and IP devised the study and provided the methodological and statistical analyses. MAP, TB, JK and RL substantially participated in data collection and chart reviews. AMK, MR, RK and IP and drafted the manuscript and all authors contributed to its revision. All authors read and approved the manuscript.

\section{Authors' information}

AMK is working as a senior acute neurologist in Kuopio University Hospital ED and ICU; RK is a neurologist and professor of clinical epileptology in the University of Eastern Finland and Head of Department in Kuopio University Hospital Epilepsy Center; Ilkka Parviainen is Head of Department of Kuopio University Hospital ICU and Matti Reinikainen is Head of Department of ICU in North Karelia Central Hospital. MPA, TB, JK and RL are intensive care physicians in the other four Finnish university hospital ICUs (Tampere, Helsinki, Oulu, Turku).

\section{Competing interests}

AMK has received speaker's honoraria from Orion, UCB, and MSD. RK has received speaker's honoraria from Eisai, UCB, and Orion, honoraria for membership of advisory boards from Eisai, Fennomedical, GW

Pharmaceuticals, Pfizer, Sage Therapeutics, Sandoz and UCB and research support for her institute from the Academy of Finland, Vaajasalo Foundation, Saastamoinen Foundation, UCB, and Eisai. MAP, TB, IP, JK, RL and MR have no disclosures.

\section{Consent for publication}

Not applicable. This manuscript does not contain data on any individual person. Consent from patients was not needed.

\section{Ethics approval and consent to participate}

This study received FICC Board approval to access the database, while the authorities responsible for specific hospital districts authorised the use of medical records data. This was a retrosepctive registry study; no consent was needed from patients. 


\section{Author details}

'Epilepsy Center, Neurocenter, Department of Neurology, Kuopio University Hospital, Kuopio, Finland. ${ }^{2}$ Epilepsy Center, Neurocenter, Department of Neurology, Kuopio University Hospital and Faculty of Health Sciences, School of Medicine, Institute of Clinical Medicine, University of Eastern Finland, Box 100, Kuopio 70029, KYS, Finland. ${ }^{3}$ Department of Intensive Care, Kuopio University Hospital and Faculty of Health Sciences, School of Medicine, Institute of Clinical Medicine, University of Eastern Finland, Kuopio, Finland. ${ }^{4}$ Division of Intensive Care, Tampere University Hospital, Tampere, Finland. ${ }^{5}$ Departments of Internal Medicine, Helsinki University Hospital, Helsinki, Finland. ${ }^{6}$ Department of Anesthesiology, Division of Intensive Care Medicine, Oulu University Hospital, Oulu, Finland. ${ }^{7}$ Division of Perioperative Services, Intensive Care and Pain Medicine, Turku University Hospital, Turku, Finland. ${ }^{8}$ Department of Intensive Care, North Karelia Central Hospital and Faculty of Health Sciences, School of Medicine, Institute of Clinical Medicine, University of Eastern Finland, Joensuu, Finland.

Received: 6 January 2017 Accepted: 28 February 2017

Published online: 23 March 2017

\section{References}

1. Trinka E, Kalviainen R. 25 Years of advances in definition, classification and treatment of status epilepticus. England; Elsevier Ltd; 2017. Seizure. 44, pp. 65-73. British Epilepsy Association.

2. Trinka $E$, Cock $H$, Hesdorffer $D$, et al. A definition and classification of status epilepticus - report of the ILAE Task Force on Classification of Status Epilepticus. Epilepsia. 2015;56:1515-23. doi:10.1111/epi.13121.

3. Trinka E, Hofler J, Zerbs A. Causes of status epilepticus. Epilepsia. 2012;53 Suppl 4:127-38. doi:10.1111/j.1528-1167.2012.03622.x.

4. Shorvon S, Ferlisi M. The outcome of therapies in refractory and superrefractory convulsive status epilepticus and recommendations for therapy. Brain. 2012;135:2314-28. doi:10.1093/brain/aws091.

5. Sutter R, Marsch S, Fuhr P, Ruegg S. Mortality and recovery from refractory status epilepticus in the intensive care unit: a 7-year observational study. Epilepsia. 2013:54:502-11. doi:10.1111/epi.12064.

6. Novy J, Logroscino G, Rossetti AO. Refractory status epilepticus: a prospective observational study. Epilepsia. 2010;51:251-6. doi:10.1111/j.15281167.2009.02323.x

7. Kamppi L, Mustonen $\mathrm{H}$, Soinila S. Analysis of the delay components in the treatment of status epilepticus. Neurocrit Care. 2013;19:10-8. doi:10.1007/ s12028-013-9862-X.

8. Delanty N, French JA, Labar DR, Pedley TA, Rowan AJ. Status epilepticus arising de novo in hospitalized patients: an analysis of 41 patients. Seizure. 2001:10:116-9. doi:10.1053/seiz.2000.0482.

9. Kalviainen R, Eriksson K, Happola O, et al. Update on current care guidelines. The treatment of status epilepticus. Duodecim. 2009;125:2469-71.

10. Kalviainen R, Eriksson K, Parviainen I. Refractory generalised convulsive status epilepticus: a guide to treatment. CNS Drugs. 2005;19:759-68.

11. Claassen J, Hirsch LJ, Emerson RG, Mayer SA. Treatment of refractory status epilepticus with pentobarbital, propofol, or midazolam: a systematic review. Epilepsia. 2002;43:146-53

12. Legriel S, Oddo M, Brophy GM. What's new in refractory status epilepticus? Intensive Care Med. 2016. doi:10.1007/s00134-016-4501-6.

13. Brophy GM, Bell R, Claassen J, et al. Guidelines for the evaluation and management of status epilepticus. Neurocrit Care. 2012;17:3-23. doi:10. 1007/s12028-012-9695-z

14. Logroscino G, Hesdorffer DC, Cascino G, Annegers JF, Hauser WA. Short-term mortality after a first episode of status epilepticus. Epilepsia. 1997;38:1344-9.

15. Logroscino G, Hesdorffer DC, Cascino GD, Annegers JF, Bagiella E, Hauser WA. Long-term mortality after a first episode of status epilepticus. Neurology. 2002;58:537-41.

16. Kantanen AM, Reinikainen M, Parviainen I, et al. Incidence and mortality of super-refractory status epilepticus in adults. Epilepsy Behav. 2015;49:131-4. doi:10.1016/j.yebeh.2015.04.065.

17. Reinikainen M, Mussalo P, Hovilehto S, et al. Association of automated data collection and data completeness with outcomes of intensive care. A new customised model for outcome prediction. Acta Anaesthesiol Scand. 2012;56:1114-22. doi:10.1111/j.1399-6576.2012.02669.x.

18. Knaus WA, Draper EA, Wagner DP, Zimmerman JE. Prognosis in acute organ-system failure. Ann Surg. 1985;202:685-93.
19. Le Gall JR, Lemeshow S, Saulnier F. A new Simplified Acute Physiology Score (SAPS II) based on a European/North American multicenter study. JAMA. 1993;270:2957-63.

20. Vincent $J$, de Mendonca A, Cantraine F, et al. Use of the SOFA score to assess the incidence of organ dysfunction/failure in intensive care units: results of a multicenter, prospective study. Working group on 'sepsis-related problems' of the European Society of Intensive Care Medicine. Crit Care Med. 1998;26:1793-800.

21. Delaj L, Novy J, Ryvlin P, Marchi NA, Rossetti AO. Refractory and superrefractory status epilepticus in adults: a 9-year cohort study. Acta Neurol Scand. 2017:135(1):92-99. doi:10.1111/ane.12605.

22. Hay A, Bellomo R, Pilcher D, Jackson G, Kaukonen K-M, Bailey M. Characteristics and outcome of patients with the ICU admission diagnosis of status epilepticus in Australia and New Zealand. J Crit Care. 2016;34:146-53. doi:10.1016/j.jcrc.2016.03.003.

23. Madžar D, Geyer A, Knappe RU, et al. Association of seizure duration and outcome in refractory status epilepticus. J Neurol. 2016;263:485-91. doi:10.1007/s00415-015-7992-0.

24. Hocker SE, Britton JW, Mandrekar JN, Wijdicks EFM, Rabinstein AA. Predictors of outcome in refractory status epilepticus. Arch Neurol. 2013;70:72-7. doi:10.1001/jamaneurol.2013.578.

25. Giovannini G, Monti G, Polisi MM, et al. A one-year prospective study of refractory status epilepticus in Modena, Italy. Epilepsy Behav. 2015;49:141-5. doi:10.1016/j.yebeh.2015.05.022.

26. Marchi NA, Novy J, Faouzi M, Stähli C, Burnand B, Rossetti AO. Status epilepticus: impact of therapeutic coma on outcome. Crit Care Med. 2015; 43(5):1003-1009. doi:10.1097/CCM.0000000000000881. ISSN: 0090-3493.

27. DeLorenzo RJ, Hauser WA, Towne AR, et al. A prospective, population-based epidemiologic study of status epilepticus in Richmond, Virginia. Neurology. 1996;46:1029-35.

28. Towne AR. Epidemiology and outcomes of status epilepticus in the elderly. Int Rev Neurobiol. 2007:81:111-27.

29. Rossetti AO, Hurwitz S, Logroscino G, Bromfield EB. Prognosis of status epilepticus: role of aetiology, age, and consciousness impairment at presentation. J Neurol Neurosurg Psychiatry. 2006:77:611-5.

30. Ong C, Sheu S, Tsai C, Wong Y, Chen SC. Age-dependent sex difference of the incidence and mortality of status epilepticus: a twelve year nationwide population-based cohort study in Taiwan. PLoS One. 2015;10. 10.1371/ journal.pone.0122350.

31. Haas B, Wunsch $\mathrm{H}$. How does prior health status (age, comorbidities and frailty) determine critical illness and outcome? Curr Opin Crit Care. 2016:22:500-5. doi:10.1097/MCC.0000000000000342.

32. Heyland DK, Garland A, Bagshaw SM, et al. Recovery after critical illness in patients aged 80 years or older: a multi-center prospective observational cohort study. Intensive Care Med. 2015;41:1911-20. doi:10.1007/s00134-0154028-2.

33. Nisula S, Kaukonen KM, Vaara ST, et al. Incidence, risk factors and 90-day mortality of patients with acute kidney injury in Finnish intensive care units: the FINNAKI study. Intensive Care Med. 2013;39:420-8. doi:10.1007/s00134012-2796-5

34. Sutter R, Kaplan PW, Ruegg S. Outcome predictors for status epilepticus what really counts. Nat Rev Neurol. 2013;9:525-34. doi:10.1038/nrneurol. 2013.154.

35. Patel M, Bagary M, McCorry D. The management of convulsive refractory status epilepticus in adults in the UK: no consistency in practice and little access to continuous EEG monitoring. Seizure. 2015;24:33-7. doi:10.1016/j. seizure.2014.11.005.

36. Kamppi L, Mustonen H, Soinila S. Factors related to delays in pre-hospital management of status epilepticus. Neurocrit Care. 2015:22:93-104. doi:10.1007/s12028-014-0016-6.

37. Drislane FW, Blum AS, Lopez MR, Gautam S, Schomer DL. Duration of refractory status epilepticus and outcome: loss of prognostic utility after several hours. Epilepsia. 2009;50:1566-71. doi:10.1111/j.1528-1167.2008. $01993 x$ 